\title{
Imaging Evaluation of Paediatric Patients with Spinal Dysraphism: A Prospective Observational Study
}

\author{
Sultana $\mathrm{N}^{1^{*}}$, Rima $\mathrm{S}^{2}$, Zubery $\mathrm{M} \mathrm{H}^{3}$, Jabeen $\mathrm{S}^{4}$, Rana R A ${ }^{5}$, Faruque $\mathrm{M} \mathrm{A}^{6}$, Rahman $\mathrm{S}^{7}$, Islam $\mathrm{MK}^{8}$
}

\author{
${ }^{1}$ Dr. Nasim Sultana, Associate Professor, Dept. of Radiology and Imaging, BSMMU, Bangladesh \\ ${ }^{2}$ Dr. Shamim Rima, Assistant Professor, Dept. of Radiology and Imaging, Anwer Khan Modern Medical College and Hospital, Dhaka, Bangladesh \\ ${ }^{3}$ Dr. Md Husnaion Zubery, Medical Officer, DGHS, Dhaka, Bangladesh \\ ${ }^{4}$ Dr. Shaila Jabeen, Consultant Radiologist, Ibn Sina Diagnostic and Consultation Centre, Dhaka, Bangladesh \\ ${ }^{5}$ Dr. Rubina Afroz Rana, Assistant Professor, Dept. of Paediatrics, NCCRF\& HD, Dhaka, Bangladesh \\ ${ }^{6}$ Dr. Md Aktar Faruque, Resident Physician (Paediatrics), Rangpur Medical College Hospital. Rangpur, Bangladesh \\ ${ }^{7}$ Lt Col Sonia Rahman, Classified Radiologist, CMH, Cumilla Cantonment, Cumilla, Bangladesh \\ ${ }^{8}$ Maj Mohammad Khairul Islam, Classified Radiologist, CMH, Ramu Cantonment, Cox's Bazar, Bangladesh
}

DOI: $10.36347 /$ sjams.2020.v08i12.008

| Received: 26.11.2020 | Accepted: 08.12.2020 | Published: 10.12.2020

*Corresponding author: Dr. Nasim Sultana

Abstract

Original Research Article

Background: Spinal dysraphism includes a spectrum of congenital disorders caused by incomplete or abnormal closure of the neural tube during early embryogenesis. As a result, fusion of the midline spinal elements is either absent or incomplete. MRI (Magnetic resonance imaging) is an excellent imaging modality to visualize the spinal cord of patients of all ages. Although worldwide it is considered as imaging modality of choice for defining spinal dysraphism we have very few information regarding this issue. Aim of the study: The aim of this study was to assess the role of MRI in the evaluation of spinal dysraphism in paediatric patients. Methods: This was a descriptive observational study which was conducted in the Department of Radiology and Imaging, Bangabandhu Sheikh Mujib Medical University (BSMMU), Bangladesh during the period from July 2015 to June 2016. In total 47 paediatric patients presented with a clinical diagnosis of spinal dysraphism and referred to the Department of Radiology and Imaging, BSMMU for MRI were selected as study population. All patients underwent a detailed physical examination, followed by MRI. All data were collected, processed, analyzed and disseminated by MS Office and SPSS version 16 as per need. Result: In this study we found $42.55 \%$ patients were with open and $57.45 \%$ were with closed dysraphism. Among total study people in $36.17 \%, 4.26 \%$ and $2.13 \%$ participant meningomyelocele, myelocele and hemimyelocele were associated as features respectively. Among total study people in $8.51 \%, 6.38 \%, 17.02 \%, 4.26 \%$ and $21.28 \%$ participant lipomyelomeningocele, meningocele, diastematomyelia, filum terminale lipoma and dorsal dermal sinus were associated as features respectively. In analyzing the levels of spinal involvement among participants we observed, in $47 \%, 38 \%, 11 \%$ and $4 \%$ patients lumber, sacral thoracic and cervical dysraphism were found respectively. Conclusion: Paediatric spinal dysraphism as well as associated malformations or features are accurately diagnosed on MRI scan. MR myelographic 3D-HASTE and STIR sequences should be a part of protocol to evaluate spinal dysraphism. An organized approach and MRI can helps in making the correct diagnosis as it does not involve ionizing radiation, is advanced and safe modality for assessing the spinal cord at all ages and defining complex spinal dysraphism.

Keywords: Imaging, MRI, Radiology, Paediatric, Spinal dysraphism.

Copyright $(\mathcal{C} 2020$ The Author(s): This is an open-access article distributed under the terms of the Creative Commons Attribution 4.0 International License (CC BY-NC 4.0) which permits unrestricted use, distribution, and reproduction in any medium for non-commercial use provided the original author and source are credited.

\section{INTRODUCTION}

Spinal dysraphism includes a spectrum of congenital disorders caused by incomplete or abnormal closure of the neural tube during early embryogenesis. As a result, fusion of the midline spinal elements is either absent or incomplete. MRI (Magnetic resonance imaging) is an excellent imaging modality to visualize the spinal cord of patients of all ages. Although worldwide it is considered as imaging modality of choice for defining spinal dysraphism we have very few information regarding this issue. Spinal dysraphism includes spectrum of congenital fusion anomalies of one or more dorsal midline structures including osseous, mesenchymal and nervous tissue [1]. Clinical description of spinal dysraphism was made by Lichtenstein BW and James CC et al., [2]. Early imaging approaches were based on the use of conventional Radiography, Ultrasonography (USG) and Computerized tomography (CT) [3]. MRI of spinal dysraphism is first described by Barnes PD et al., [4]. 
Spinal dysraphism is one of the most common congenital disorders associated with significant mortality and morbidity. The estimated incidence of spinal dysraphism is about 1-3/1000 live births [5]. About $55-70 \%$ of neural tube defects occur in females. Variations in prevalence based on race, ethnicity, gender and region have also been reported [6]. The prevalence of neural tube defects (including anencephaly and spinal dysraphisms) has been on the decline during the last 25 years as a result of antenatal screening and folic acid supplementation [7]. Majority of the closed spinal dysraphic states are asymptomatic at birth. They are suspected in the presence of high risk cutaneous markers, or when these children present with neurological deficit later in life [8]. MRI is the assessment of choice because of its better investigative performance, exceptional soft tissue characterization and importance in presurgical planning [5]. MRI is the imaging modality of choice in the diagnosis and characterization of spinal dysraphism. Rest of the modalities play a supplemental role. Antero-posterior and lateral plain radiographs are a must for evaluation of the vertebral column [9]. In cases of diastematomyelia, bony spur may be seen. Radiographs are used as screening examinations to guide the further imaging work-up. Ultrasonography is useful in the antenatal diagnosis of spinal dysraphism and is also of some use in the neonate and infant [10]. Prenatal ultrasonography can detect the open widened neural arch, with flared laminae, can show the meningomyelocele sac and detect hydrocephalus and associated cranial anomalies. Direct ultrasonography of the sac in children using high frequency transducers gives information about the contents of the sac. But, for complete and detailed information, an MRI scan is often required. In cases of split cord malformation, CT is useful in demonstration of the bony spur. Prior to the advent of MRI, myelography and post-myelogram CT were used. MRI gives a non-invasive and accurate method to evaluate spinal dysraphism, thus making it the modality of choice. The excellent contrast resolution, wide field of view and multi-planar images help evaluate the entire spinal cord, contents of the back mass; detect cord tethering, associated syringomyelia. For the demonstration of syrinx and associated pathologies like dermoid and epidermoid cyst, T2W images are helpful [11]. Patients with spinal dysraphism can have multiple spinal anomalies. For example, a patient with myelomeningocele may have associated chiari malformation or syringohydromyelia. Fetal MRI may be used as complimentary modality to USG for the antenatal diagnosis of spinal anomalies and associated hydrocephalus [10].

\section{OBJECTIVES \\ General Objective}

- To assess the role of MRI in the evaluation of spinal dysraphism in paediatric patients.

\section{SPECIFIC OBJECTIVE}

- To collect information regarding age and gender of spinal dysraphism in paediatric patients.

- To collect information regarding dysraphism types among spinal dysraphism in paediatric patients.

- To collect information regarding Level of spinal involvement among spinal dysraphism in paediatric patients.

\section{Methodology \& Materials}

This was a descriptive observational study which was conducted in the Department of Radiology and Imaging, Bangabandhu Sheikh Mujib Medical University (BSMMU), Bangladesh during the period from July 2015 to June 2016. In total 47 patients presented with a clinical diagnosis of spinal dysraphism and referred to the Department of Radiology and Imaging, BSMMU for MRI were selected as study population. Proper written consents were taken in favor of all the participants before starting data collection. A pre-designed questioner was used in collecting patient data. In this study newborn-12 years old suspected to have spinal dysraphism and patient diagnosed to have physical abnormality caused by congenital lesions of spinal cord and cauda equina were included. On the other hand, patients with anencephaly and patients with physical abnormality due to spinal neoplasms, Friedreich's ataxia, cerebral palsy, old poliomyelitis and local conditions of the feet were excluded. All patients underwent a detailed physical examination, followed by MRI. The standard spine imaging included sagittal, fast spin-echo T1- and T2-W (weighted) sequences were assessed. Both axial T1-W and T2-W images were acquired. Group of axial images through disc level were not applied, unlike most adult spine imaging protocols, because degenerative disc disease is uncommon. Children with suspected spinal dysraphism and/or scoliosis routinely had axial $\mathrm{T} 1-\mathrm{W}$ images to detect lipomas of the filum terminal that may not be visible on sagittal imaging. MR myelographic 3D-HASTE and STIR sequences tests were performed and analyzed. All data were collected, processed, analyzed and disseminated by MS Office and SPSS version 16 as per need.

\section{RESULT}

In this study $48.94 \%$ participants were from 1 5 years' age group which was the highest number from a single age group. Then $21.28 \%$, and $29.79 \%$ participants were from $0-1$ years' and $>5$ years' age groups respectively. The mean $( \pm \mathrm{SD})$ age of the total participants was $3.71 \pm 1.15$ years. In analyzing the gender of the participants we found $36 \% \quad(n=17)$ participants were male whereas $64 \% \quad(n=30)$ were female. The male-female ratio was $1: 1.76$. So female were dominating in number. In analyzing the types of 
dysraphism among total study population we found $42.55 \%$ patients were with open dysraphism whereas $57.45 \%$ patients were with closed dysraphism. Among patients with open dysraphism meningomyelocele, myelocele and hemimyelocele were associated as features. Among total study people in $36.17 \%$, $4.26 \%$ and $2.13 \%$ participant meningomyelocele, myelocele and hemimyelocele were associated as features respectively. On the other hand among patients with closed dysraphism lipomyelomeningocele, meningocele, diastematomyelia, filum terminale lipoma and dorsal dermal sinus were associated as features. Among total study people in $8.51 \%, 6.38 \%, 17.02 \%$, $4.26 \%$ and $21.28 \%$ participant lipomyelomeningocele, meningocele, diastematomyelia, filum terminale lipoma and dorsal dermal sinus were associated as features respectively. In analyzing the levels of spinal involvement among participants we observed, in $47 \%$, $38 \%, 11 \%$ and $4 \%$ patients lumber, sacral thoracic and cervical dysraphism were found respectively.

Table-1: Age distribution of participants $(\mathrm{N}=47)$

\begin{tabular}{|l|l|l|}
\hline Age & $\mathbf{n}$ & $\mathbf{\%}$ \\
\hline 0-1 year & 10 & 21.28 \\
\hline 1-5 years & 23 & 48.94 \\
\hline$>$ 5 years & 14 & 29.79 \\
\hline Total & $\mathbf{4 7}$ & $\mathbf{1 0 0}$ \\
\hline
\end{tabular}

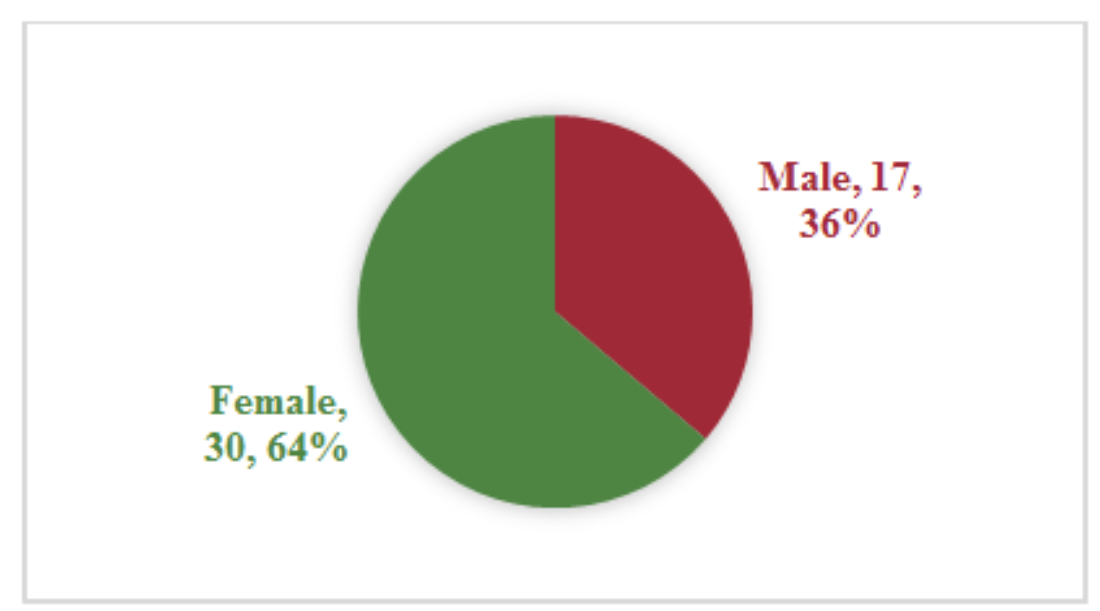

Fig-1: Gender distribution of the participants $(n=47)$

Table-2: Distribution of dysraphism types among participants $(\mathrm{N}=47)$

\begin{tabular}{|l|l|l|l|}
\hline \multirow{2}{*}{ Type (n, \%) } & Features & \multicolumn{2}{|l|}{} \\
\cline { 2 - 4 } & Title & $\mathrm{n}$ & $\%$ \\
\hline \multirow{3}{*}{ Open (20, 42.55\%) } & Meningomyelocele & 17 & 36.17 \\
\cline { 2 - 4 } & Myelocele & 2 & 4.26 \\
\cline { 2 - 4 } & Hemimyelocele & 1 & 2.13 \\
\hline Closed (27, 57.45\%) & Lipomyelomeningocele & 4 & 8.51 \\
\cline { 2 - 4 } & Meningocele & 3 & 6.38 \\
\cline { 2 - 5 } & Diastematomyelia & 8 & 17.02 \\
\cline { 2 - 4 } & Filum terminale lipoma & 2 & 4.26 \\
\cline { 2 - 4 } & Dorsal dermal sinus & 10 & 21.28 \\
\hline Total & & 47 & 100 \\
\hline
\end{tabular}

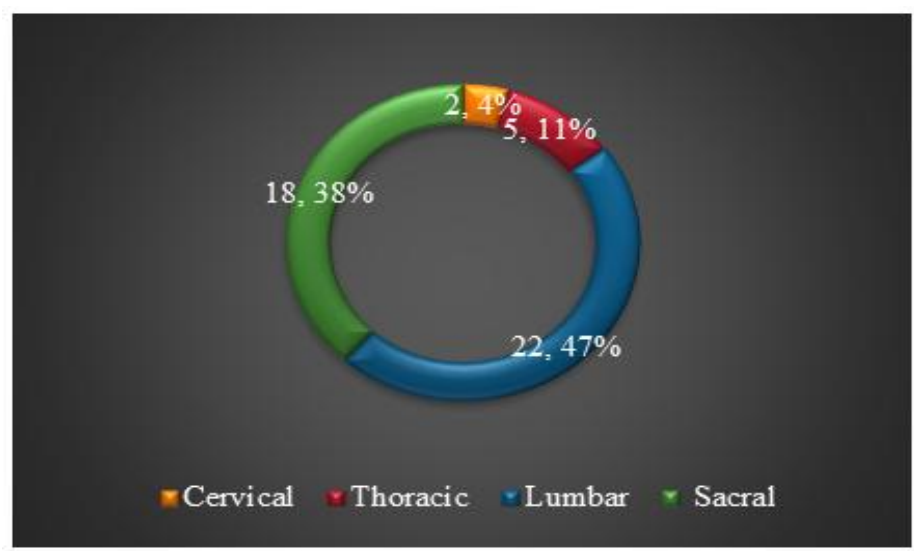

Fig-2: Level of spinal involvement among participants $(n=47)$ 


\section{DISCUSSION}

The aim of this study was to assess the role of MRI in the evaluation of spinal dysraphism paediatric patients. Spinal dysraphisms are the congenital abnormalities of the spine and spinal cord. The age of the patients in present study ranged from newborn to 12 years. In our study $48.94 \%$ participants were from 1-5 years' age group which was the highest number from a single age group. Then $21.28 \%$, and $29.79 \%$ participants were from $0-1$ years' and $>5$ years' age groups respectively. The mean $( \pm \mathrm{SD})$ age of the total participants was $3.71 \pm 1.15$ years. In a study by Kumari MV et al., age of the patients ranged from 17 days to 13 years [5]. In our study out of 47 patients, $20(42.55 \%)$ had open spinal dysraphisms and $27(57.45 \%)$ had closed dysraphisms. The results were similar to study by Kumari MV et al., in which $38(57.5 \%)$ were open spinal dysraphisms and $28(42.4 \%)$ were closed dysraphisms [5]. Children of spinal dysraphism present with clinical features like swelling on the back, dermal sinus, haemangioma, dimple, lower limb weakness as well as bowel and bladder incontinence. In this study, swelling in the back is the most common clinical feature which constituted $29(62 \%)$ patients. In a study by Kumari MV et al., also swelling in the back was the most common clinical feature which constituted 51 (77.2\%) patients ${ }^{5}$. In this study we found $42.55 \%$ patients were with open and $57.45 \%$ were with closed dysraphism. Among total study people in $36.17 \%$, $4.26 \%$ and $2.13 \%$ participant meningomyelocele, myelocele and hemimyelocele were associated as features respectively. Among total study people in $8.51 \%, 6.38 \%, 17.02 \%, 4.26 \%$ and $21.28 \%$ participant lipomyelomeningocele, meningocele, diastematomyelia, filum terminale lipoma and dorsal dermal sinus were associated as features respectively. But in a study by Kumari MV et al., myelomeningocele was the most common dysraphism which constituted 38 (57.5\%) [5]. In a study by Nafees $\mathrm{M}$ et al., also myelomeningocele is the most common dysraphism which constituted 29 $(39.2 \%)$ [12]. In our study in analyzing the levels of spinal involvement among participants we observed, in $47 \%, 38 \%, 11 \%$ and $4 \%$ patients lumber, sacral thoracic and cervical dysraphism were found respectively. In a study by Nafees $\mathrm{M}$ et al., also lumbosacral region was the most common location which constituted 38 $(51.4 \%)$ and in study by Kumari MV et al., it was seen in $20(52.6 \%)$ patients [12]. Of which type 2 constituted $75 \%$ and type 1 constituted $25 \%$ and in a study by Nishtar $\mathrm{T}$ et al., of the 53 patients 2 (4\%) Diastematomyelia patients were detected [13]. Open defects are associated with abnormalities such as hydrocephalus, Arnold-Chiari, syrinx. In our study Arnold-Chiari type 2 constituted $15 \%$. In a study by Kumari MV et al., Arnold- Chiari type 2 constituted 6 $(15.7 \%)$ and in a study by Kumar R et al., ArnoldChiari type 2 constituted 62 (45\%) patients [14].

\section{LIMITATIONS OF THE STUDY}

This is a single center study with small sample size. So, the finding may not be reflected in the whole country.

\section{CONCLUSION AND RECOMMENDATIONS}

Paediatric spinal dysraphism as well as associated malformations or features are accurately diagnosed on MRI scan. MR myelographic 3D-HASTE and STIR sequences should be a part of protocol to evaluate spinal dysraphism. An organized approach and MRI can helps in making the correct diagnosis as it does not involve ionizing radiation, is advanced and safe modality for assessing the spinal cord at all ages and defining complex spinal dysraphism. But this was a single centered study with a small sized sample. So the findings of this study may not reflect the exact scenario of the whole country. So, for getting more specific findings we would like to recommend for conducting more studies regarding the same issue.

\section{Source of Funding: Self}

Conflict of interest: None declared

\section{REFERENCES}

1. Grainger R, Allison D, Adam A. Grainger's and Allison's diagnostic radiology. Newyork: Churchill Livingstone; 2001; 802-805.

2. James CC, Lassman LP. Spinal dysraphism: an orthopaedic syndrome in children accompanying occult forms. Paediatric Radiol. 1960; 35:315-27.

3. Naidich TP, McLone DG, Mutluer SA. New understanding of dorsal dysraphism with lipoma (lipomyeloschisis): radiologic evaluation and surgical correction. AJR. 1983; 140:1065-78.

4. Barnes PD, Lester PD, Yamanashi WS, Prince JR. MRI in infants and children with spinal dysraphism. AJR. 1986; 147:339-46.

5. Kumari MV, Supriya P, Chandra Aemjal S, Raghavendra Y. Role of MRI in evaluation of suspected spinal dysraphism. Journal of Evolution of Medical and Dental Sciences. 2016; 5(17):879-84.

6. Shin M, Besser L, Siffel C, Kucik J, Shaw G, $\mathrm{Lu} \mathrm{C}$, et al. Prevalence of spina bifida among children and adolescents in 10 regions in the United States. Paediatrics. 2010; 126(2):274-79.

7. Badve C, Khanna P, Phillips G, Thapa M, Ishak G. MRI of closed spinal dysraphisms. Paediatric Radiology. 2011; 41(10):1308-20.

8. Drolet B. Birthmarks to worry about. Dermatologic Clinics. 1998; 16(3):447-53.

9. Tortori-Donati P, Rossi A, Cama A. Spinal dysraphism: a review of neuroradiological features with embryological correlations and proposal for a new classification. Neuroradiology. 2000; 42(7):471-91. 
10. Von Koch C, Glenn O, Goldstein R, Barkovich A. Fetal magnetic resonance imaging enhances detection of spinal cord anomalies in patients with sonographically detected bony anomalies of the spine. Journal of Ultrasound in Medicine. 2005; 24(6):781-89.

11. Rossi A, Biancheri R, Cama A, Piatelli G, Ravegnani M, Tortori-Donati P. Imaging in spine and spinal cord malformations. European Journal of Radiology. 2004; 50(2):177-200.

12. Nafees M, Akram MH, Abbas G. MR image spectrum of spinal dysraphism in a military hospital. A Journal of Army Medical Corps. 2012; 62(1):74-78.

13. Nishtar T, Elahi A, Iqbal N. To determine the frequency of accuracy of MRI in diagnosis of rare disorder of spinal dysraphism. J Med Sci (Peshawar, Print). 2011; 19(4):195-99.

14. Raj Kumar, Singh SN. Spinal dysraphism: Trends in Northern India Journal: Paediatric Neurosurgery - Paediat Neurosurg. 2003; 38(3):133-145. 